\title{
Carbonisation and morphological changes in modern dehusked and husked Triticum dicoccum and Triticum aestivum grains
}

\author{
Freek Braadbaart
}

Received: 17 July 2007 / Accepted: 24 September 2007/Published online: 23 October 2007

(C) Springer Verlag 2007

\begin{abstract}
Modern Triticum dicoccum and Triticum aestivum grains, with and without glumes, were subjected to experimental carbonisation under anoxic conditions. Experimental variables were the presence or absence of glumes, temperature, exposure time and heating rate. The maximum temperature was $600^{\circ} \mathrm{C}$, the time of exposure was $60 \mathrm{~min}$ and the heating rate between 1 and $100^{\circ} \mathrm{C} / \mathrm{min}$. Length, width, area, mass loss and reflectance of uncarbonised and carbonised grains were measured as a function of the variables. The main effects of charring are an increase in width, decrease in length and formation of protrusions. Reflectance measurements allow for the determination of the temperature at which carbonisation occurred. The occurrence of protrusions on the pericarp, longitudinal imprints in the pericarp and concave flanks are observed and discussed. The calculated shape factor $100 L / W$ is a useful tool for distinguishing between $T$. dicoccum and $T$. aestivum grains in samples that contain at least thirty specimens, but for single grains this method is problematic.
\end{abstract}

Keywords Charring - Shape - Identification · Archaeobotany · Triticum dicoccum - Triticum aestivum

\section{Introduction}

Triticum L. (wheat) has been a staple food for large portions of the world population since the beginning of

F. Braadbaart ( $\square)$

Department of Earth Sciences,

Geochemistry, Faculty of Geosciences,

Utrecht University, P.O. Box 80021, 3058, TA,

Utrecht, The Netherlands

e-mail: brabra@wxs.nl agriculture. Farmers grew a range of forms, and understanding differences in the relative abundance of various wheat taxa can contribute to the investigation of changes in ancient agricultural practices and diet (Hillman et al. 1996). Identification of different wheat taxa is difficult because there are a wide range of closely related taxa. The basis of identification is comparison with living material of known identity, whereby the species can sometimes be determined from the morphological characteristics of the spikes and the grains. These remains usually survive the physical and chemical decomposition associated with burial in the soil at an archaeological site through carbonisation or charring. This process can be described as the thermal conversion of the main constituents of the tissues of rachis elements, glumes and grains polysaccharides and proteins, when heated under reducing or anoxic conditions.

When rachis remains are present in a sample recovered from an archaeological site, there is general agreement that hulled wheats can be distinguished from their free-threshing counterparts, and that the ploidy level can be determined from the rachis (Hillman 2001). The identification of wheat grains, however, is far more problematic, in particular when carbonisation has distorted the grains. An earlier study reports on the effects of charring temperature on wheat grains (Braadbaart et al. 2004). The results showed the occurrence of bulges of black material as protrusions on the pericarp, and the almost identical shape at higher temperatures of grains of three species, Triticum dicoccum, T. aestivum and T. durum. It was suggested that these differences could be explained not only by the temperature to which they had been heated, but also the time of exposure or the rate of heating. The presence or absence of glumes on the grains may also have an impact. 
This paper reports a further series of experiments, which explored the impact of temperature, charring time, rate of increase in charring temperature, and presence and absence of glumes. Particular attention was given to their impact on grain shape as measured by length to width ratio (expressed as $100 \times$ length/width).

For this pilot study two species of wheat were used, T. dicoccum Schübl. (emmer wheat), a hulled, tetraploid species, and Triticum aestivum L. (bread wheat), a free threshing, hexaploid species.

\section{Material and methods}

Triticum dicoccum was donated by Mrs G. Dolci, Monteleone di Spoleto (Trivio) Pg, Italy, an area in which it has been long cultivated (Papa 1995). The wheat was grown at a height of about $1,000 \mathrm{~m}$ a.s.l. and harvested in the summer of 2004.

For the selection of $T$. aestivum for the experiments, it is important to note that when grains of modern varieties of T. aestivum are carbonised, the residues show features that are usually not observed in grains recovered from archaeological sites. A reason for this phenomenon could be the high starch content or a less rigid pericarp in modern varieties.

Sunnan, the variety of $T$. aestivum used for the experiments, is a less modern variety, originally from Sweden, and introduced to The Netherlands around 1990. It is grown by the foundation "Zeeuwse Vlegel", Goes, The Netherlands. Mr J. de Koeijer from Brouwershaven, The Netherlands, donated the sample, which was harvested in the summer of 2005.

\section{Experimental varieties}

\section{Temperature}

The samples were heated in a tube oven under a constant flow of nitrogen. In other types of ovens, such as a muffle furnace, the necessary anoxic conditions are not always ensured (Braadbaart 2004). Earlier studies have shown that results obtained from the simulation in a tube oven are comparable to situations in which the carbonisation occurs under less controlled conditions, such as in an open fire (Braadbaart 2004, chapter 7).

Although as a result of carbonisation the physical properties and the chemical structure of wheat grains change continuously with increasing temperature, five stages can be recognized that react to influences from outside in an identical manner (Braadbaart et al. 2004). Based on this, three temperatures were selected: 310,440 and $600^{\circ} \mathrm{C}$. At $310^{\circ} \mathrm{C}$ the conversion of starch and proteins, present in wheat grains, into aromatic compounds is almost completed. This makes this kind of residue more resistant to attacks by micro-organisms when deposited in the soil and the chances that this material will be recovered from archaeological sites are much greater compared to material that consists of starch and proteins. The temperature of $440^{\circ} \mathrm{C}$ was selected because the chemical structure, which now consists of condensed aromatic compounds, will not change further at higher temperatures. Moreover, the results of reflectance measurements on samples recovered from archaeological sites show that the majority had been carbonised around this temperature (Braadbaart unpublished). At higher temperatures, the chemical composition does not change further, while the reflectance still increases. As $600^{\circ} \mathrm{C}$ seems to be a maximum temperature that can be reached when samples are heated in an open fire, this temperature was also selected.

To place these results based on the three selected temperatures in the broader perspective of a complete range of temperatures, additional experiments were performed in which separate samples of 30 dehusked grains of $T$. dicoccum and T. aestivum were carbonised at 130, 190, 220, $250,370,400$ and $500^{\circ} \mathrm{C}$. These samples were randomly selected from larger samples.

The time of exposure of the samples to the heat source, after the final temperature was reached, was limited for practical reasons to $60 \mathrm{~min}$ in each experiment (Braadbaart et al. 2004).

\section{Heating rate}

A high (HHR) and a low (LHR) heating rate were used for the carbonisation of wheat grains. To study the HHR, the samples were introduced into the tube oven which had been preheated to the selected temperature as mentioned above. To study the influence of the LHR, samples of grains were introduced into a tube oven that was at the ambient temperature of around $20^{\circ} \mathrm{C}$. Subsequently the samples were heated to 310,440 and $600^{\circ} \mathrm{C}$. For each temperature two heating times, 120 and $300 \mathrm{~min}$, were selected to reach the final temperature. In this way the heating rate varied from 1.0 to $5.0^{\circ} \mathrm{C} / \mathrm{min}$. After the final temperature was reached, the wheat grains were kept at this temperature for another $60 \mathrm{~min}$ in order to be able to compare the results with those obtained when heated at a HHR for $60 \mathrm{~min}$.

\section{Presencelabsence of glumes}

Samples of dehusked grains and whole spikes were used for the experiments. In the case of dehusked grains, the 
chaff was manually removed from the grains before carbonisation. The grains present in the spikes were manually dehusked after carbonisation.

\section{Excluded variables}

The size and chemical composition of the material of the samples determines its thermal properties, such as conductivity, specific heat or emissive power. In the case of wheat grains, the variation in size or chemical composition in relation to their thermal properties is rather limited and therefore it is assumed that for all the investigated grains these variables are identical (Braadbaart et al. 2005). An exception is made for the presence of glumes, as archaeological results show that dehusked wheat may have been carbonised as well as husked in spikes or spikelets (Maier 1996).

A variable that needs a closer look is the water content of uncarbonised grains, which may vary. When a sample reaches a temperature of $100^{\circ} \mathrm{C}$, the free water will be converted into vapour that disappears into the external environment. The available heat will be used for this conversion and as a result the temperature of the sample will remain stable until all the water has been removed. Next, when heat is still available, the temperature will rise again and the normal chemical reactions that are characteristic of the carbonisation process will occur. Variation in water content of uncarbonised grains will therefore not influence this process.

\section{Measurement of changes in grain}

\section{Reflectance}

The reflectance measured on carbonised organic material can be used to determine the temperature at which it has been carbonised. The main constituents of wheat grains are starch and proteins. As a result of carbonisation the chemical structure gradually changes, with increasing temperature, into aromatic structures. The aromatic rings formed in this way are more planar than their precursors and tend to align with each other causing more light to reflect. The optical properties in the form of the refractive and adsorption indices of the aromatic rings allow the measurement of reflectance.

Reflectance is defined as the percentage of vertically incident monochromatic light reflected from a highly polished surface of a sample, calibrated against the light reflected from a standard of known reflectance. From a temperature of approximately of $270^{\circ} \mathrm{C}$ onwards the formation of multi-ring (3-5) aromatic structural units causes an increase of the reflectance (Carr and Williamson 1989; Braadbaart 2004). Condensation and a further molecular reorganization with the formation of large polyaromatic sheets from about $440^{\circ} \mathrm{C}$ increase the reflectance still further.

For the determination of the reflectance (\%Rr), the following procedure was followed. From each sample carbonised at a given temperature three grains were embedded in resin blocks and polished. On each specimen one hundred randomly performed reflectance readings were made in order to obtain a statistically acceptable population, and the mean reflectance of each specimen was calculated. The reflectance was measured under oil immersion at a wavelength of $546 \mathrm{~nm}$ using a Leitz motorized DMLA microscope equipped with an xyz-stage and a Basler video camera. Preparation of polished blocks and reflectance measurements were performed according to standard methods defined in ISO 7404, part 2 (1985) and ISO 7404, part 5 (1994).

\section{Morphological features}

An earlier study describes the influence of the temperature at a high heating rate (HHR) on the dimensions of grains of three species of wheat (Braadbaart and van Bergen 2005). Briefly, the length shrinks continuously with increasing temperature, while the width shows a strong increase up to $270^{\circ} \mathrm{C}$, but decreasing above this temperature. As a result the area of the grains increases strongly up to a temperature of $250^{\circ} \mathrm{C}$, but decreases again at higher temperatures. The original area is attained between 370 and $400^{\circ} \mathrm{C}$, to shrink further at higher temperatures. In the above quoted study it was shown that the changes in the width and the height are proportional and therefore it was not necessary to measure the height of grains in addition to the width.

The swelling of wheat grains as described above causes another phenomenon, the development of bulges of black material on the pericarp. It was shown that the chemical structure of the endosperm and the black material on the outside are identical and apparently the latter originates from the endosperm (Braadbaart et al. 2005). It is interesting to note that no literature was found where grains recovered from archaeological sites are described showing protrusions, while in these carbonisation experiments in a preheated oven protrusions were rather common.

The development of longitudinal imprints on the pericarp and the change of the flanks of the grains, as a result of carbonisation, are described. It is noted that the influence of carbonisation on other characters used for the identification of wheat grains (Hillman et al. 1996), have not been investigated. 
Table 1 Properties of dehusked grains of Triticum dicoccum uncarbonised and carbonised at the indicated temperatures for 60 min at high (HHR) and low (LHR) heating rates

\begin{tabular}{|c|c|c|c|c|c|c|c|c|c|c|}
\hline $\begin{array}{l}\text { Temperature } \\
\left({ }^{\circ} \mathrm{C}\right)\end{array}$ & $\begin{array}{l}\text { Heating rate } \\
\left({ }^{\circ} \mathrm{C} / \mathrm{min}\right)\end{array}$ & $\begin{array}{l}\text { Mass loss } \\
(\%)\end{array}$ & $\% \mathrm{Rr}$ & $\begin{array}{l}L^{\mathrm{a}} \\
(\mathrm{mm})\end{array}$ & $\begin{array}{l}W^{\mathrm{a}} \\
(\mathrm{mm})\end{array}$ & $\begin{array}{l}A^{\mathrm{a}} \\
\left(\mathrm{mm}^{2}\right)\end{array}$ & $100^{\mathrm{a}} \mathrm{L} / W$ & $\begin{array}{l}\text { Degree of } \\
\text { variation } 100 L / W\end{array}$ & $\begin{array}{l}\text { Grains with } \\
\text { protrusion }(\%)\end{array}$ & $\begin{array}{l}\text { Grains with } \\
\text { longitudinal } \\
\text { imprints (\%) }\end{array}$ \\
\hline \multirow[t]{2}{*}{$u_{n c}{ }^{b}$} & NA & NA & NA & 8.08 & 2.82 & 16.0 & 287 & $242-320$ & NA & 0 \\
\hline & & & & 0.51 & 0.27 & 1.8 & & & & \\
\hline \multirow[t]{2}{*}{310} & 26(HHR) & 56.6 & 0.45 & 6.35 & 4.06 & 18.4 & 156 & $110-215$ & 81 & 0 \\
\hline & & & 0.077 & 0.76 & 0.54 & 2.6 & & & & \\
\hline \multirow[t]{2}{*}{310} & 2.4(LHR) & 54.6 & 0.41 & 6.77 & 3.86 & 18.7 & 175 & $126-225$ & 16 & 0 \\
\hline & & & 0.059 & 0.52 & 0.37 & 2.4 & & & & \\
\hline \multirow[t]{2}{*}{310} & 1(LHR) & 54.5 & 0.45 & 6.73 & 3.82 & 18.8 & 176 & $141-216$ & 3 & 0 \\
\hline & & & 0.049 & 0.48 & 0.36 & 2.4 & & & & \\
\hline \multirow[t]{2}{*}{440} & 47(HHR) & 75.9 & 1.64 & 5.91 & 3.57 & 14.8 & 166 & $130-205$ & 57 & 0 \\
\hline & & & 0.027 & 0.50 & 0.41 & 2.1 & & & & \\
\hline \multirow[t]{2}{*}{440} & 3.5(LHR) & 69.5 & 1.63 & 6.03 & 3.59 & 15.4 & 168 & $130-203$ & 11 & 0 \\
\hline & & & 0.054 & 0.52 & 0.35 & 2.2 & & & & \\
\hline \multirow[t]{2}{*}{440} & 1.4(LHR) & 67.3 & 1.64 & 6.06 & 3.37 & 14.6 & 179 & $144-225$ & 0 & 0 \\
\hline & & & 0.098 & 0.48 & 0.26 & 1.8 & & & & \\
\hline \multirow[t]{2}{*}{600} & 97(HHR) & 79.3 & 3.68 & 5.87 & 3.35 & 13.9 & 175 & $155-205$ & 13 & 0 \\
\hline & & & 0.211 & 0.50 & 0.35 & 2.1 & & & & \\
\hline \multirow[t]{2}{*}{600} & 5(LHR) & 74.3 & 3.73 & 5.59 & 3.36 & 14.1 & 168 & $146-207$ & 26 & 0 \\
\hline & & & 0.170 & 0.38 & 0.43 & 2.3 & & & & \\
\hline \multirow[t]{2}{*}{600} & 2(LHR) & 71.4 & 3.66 & 5.63 & 3.10 & 12.6 & 182 & $143-240$ & 0 & 0 \\
\hline & & & 0.183 & 0.36 & 0.33 & 1.8 & & & & \\
\hline
\end{tabular}

Italic figures below values of $\% \mathrm{Rr}, L, W$ and $A$ are standard deviations

${ }^{\mathrm{a}}$ Mean values of samples with $N=30 ;{ }^{\mathrm{b}}$ uncarbonized; $N A$ not applicable

The increasing temperature will drive the chemical reactions that convert the main constituents of wheat grains, the polysaccharides starch and cellulose and proteins, through substances with mainly aromatic constituents into a new chemically distinct material with a highly carbon-enriched character (Braadbaart et al. 2004). These conversions are accompanied by the release of a large amount of volatile compounds, which disappear into the external environment. One of the results is a mass loss that increases strongly from 220 to $270^{\circ} \mathrm{C}$ to $50 \%$; reaching $80 \%$ at $600^{\circ} \mathrm{C}$. Mass loss was measured for a group of 30 grains. Simultaneously the carbon content increases, explaining the name of the process.

To study the morphological features, 30 grains, husked and dehusked, were selected from the samples, because this was sufficient to fit a confidence interval of $95 \%$ for each measured dimension. To measure the dimensions, digital image analysis was used whereby the grains were placed on a scanner bed with the ventral side down. For all experiments the same orientation of the grains was ensured. Width, length and area of each specimen were measured and the mean calculated.
The details of these methods have been described extensively in earlier studies (Braadbaart et al. 2004, 2005; Braadbaart and van Bergen 2005).

\section{Results and discussion}

\section{Changes in morphology}

The results of the experiments performed at 310, 440 and $600^{\circ} \mathrm{C}$ at low and high heating rates are summarized in Tables 1 and 2 for dehusked and husked $T$. dicoccum grains and in Tables 3 and 4 for dehusked and husked T. aestivum grains. Because of the large number of variables ( $T$. dicoccum and T. aestivum, dehusked and husked, HHR and LHR), the changes of length and width are difficult to comprehend. Therefore the differences are expressed in percentages of the shrinkage of the length and the swelling of the width, relative to their uncarbonised values (Table 5).

The three main changes in carbonised grains are increase in width, decrease of length and the formation of external protrusions. 
Table 2 Properties of husked grains of Triticum dicoccum carbonised in spikes at the indicated temperatures for 60 min at high (HHR) and low (LHR) heating rates; further explanations see Table 1

\begin{tabular}{|c|c|c|c|c|c|c|c|c|c|c|}
\hline $\begin{array}{l}\text { Temperature } \\
\left({ }^{\circ} \mathrm{C}\right)\end{array}$ & $\begin{array}{l}\text { Heating rate } \\
\left({ }^{\circ} \mathrm{C} / \mathrm{min}\right)\end{array}$ & $\begin{array}{l}\text { Mass loss } \\
(\%)\end{array}$ & $\% \mathrm{Rr}$ & $\begin{array}{l}L^{\mathrm{a}} \\
(\mathrm{mm})\end{array}$ & $\begin{array}{l}W^{\mathrm{a}} \\
(\mathrm{mm})\end{array}$ & $\begin{array}{l}A^{\mathrm{a}} \\
\left(\mathrm{mm}^{2}\right)\end{array}$ & $100^{\mathrm{a}} \mathrm{L} / \mathrm{W}$ & $\begin{array}{l}\text { Degree of } \\
\text { variation } 100 L / W\end{array}$ & $\begin{array}{l}\text { Grains with } \\
\text { protrusion }(\%)\end{array}$ & $\begin{array}{l}\text { Grains with } \\
\text { longitudinal } \\
\text { imprints(\%) }\end{array}$ \\
\hline \multirow[t]{2}{*}{310} & 26(HHR) & 56.2 & 0.46 & 7.37 & 3.89 & 20.9 & 189 & $158-219$ & 53 & 40 \\
\hline & & & 0.057 & 0.31 & 0.27 & 1.7 & & & & \\
\hline \multirow[t]{2}{*}{310} & 2.4(LHR) & 54.4 & - & 7.53 & 3.95 & 20.2 & 191 & $174-222$ & 15 & 95 \\
\hline & & & & 0.42 & 0.27 & 2.8 & & & & \\
\hline \multirow[t]{2}{*}{440} & 47(HHR) & 73.6 & 1.64 & 6.47 & 3.26 & 15.5 & 198 & $181-230$ & 24 & 0 \\
\hline & & & 0.037 & 0.21 & 0.35 & 1.5 & & & & \\
\hline \multirow[t]{2}{*}{440} & 3.5(LHR) & 66.2 & - & 6.49 & 3.39 & 15.7 & 191 & $176-210$ & 3 & 78 \\
\hline & & & & 0.43 & 0.22 & 1.9 & & & & \\
\hline \multirow[t]{2}{*}{600} & 97(HHR) & 78.2 & 3.58 & 5.85 & 2.98 & 12.5 & 196 & $172-240$ & 11 & 0 \\
\hline & & & 0.185 & 0.31 & 0.26 & 1.4 & & & & \\
\hline \multirow[t]{2}{*}{600} & 5(LHR) & 71.4 & - & 5.85 & 3.04 & 13.0 & 192 & $173-231$ & 0 & 59 \\
\hline & & & & 0.33 & 0.29 & 1.5 & & & & \\
\hline
\end{tabular}

- Not measured

Protrusions

From temperatures of around $250^{\circ} \mathrm{C}$ and above, the volatile compounds released during carbonisation build up a pressure within the pericarp, so that the grains act as a pressure vessel. Swollen, bigger and more compact grains are the result. The pressure causes a tensile force in the pericarp, which may result in its rupture at weak spots.

Table 3 Properties of dehusked grains of T. aestivum uncarbonised and carbonised at the indicated temperatures for $60 \mathrm{~min}$ at high (HHR) and low (LHR) heating rates; further explanations see Table 1

\begin{tabular}{|c|c|c|c|c|c|c|c|c|c|c|}
\hline $\begin{array}{l}\text { Temperature } \\
\left({ }^{\circ} \mathrm{C}\right)\end{array}$ & $\begin{array}{l}\text { Heating rate } \\
\left({ }^{\circ} \mathrm{C} / \mathrm{min}\right)\end{array}$ & $\begin{array}{l}\text { Mass } \\
\text { loss }(\%)\end{array}$ & $\% \mathrm{Rr}$ & $\begin{array}{l}L^{\mathrm{a}} \\
(\mathrm{mm})\end{array}$ & $\begin{array}{l}W^{\mathrm{a}} \\
(\mathrm{mm})\end{array}$ & $\begin{array}{l}A^{\mathrm{a}} \\
\left(\mathrm{mm}^{2}\right)\end{array}$ & $100^{\mathrm{a}} \mathrm{L} / \mathrm{W}$ & $\begin{array}{l}\text { Degree of } \\
\text { variation } \\
100 L / W\end{array}$ & $\begin{array}{l}\text { Grains with } \\
\text { protrusion }(\%)\end{array}$ & $\begin{array}{l}\text { Grains with } \\
\text { longitudinal } \\
\text { imprints(\%) }\end{array}$ \\
\hline \multirow[t]{2}{*}{ unc $^{\mathrm{b}}$} & NA & NA & NA & 5.70 & 3.39 & 14.9 & 168 & $154-200$ & NA & 0 \\
\hline & & & & 0.43 & 0.38 & 2.5 & & & & \\
\hline \multirow[t]{2}{*}{310} & 26(HHR) & 57.3 & 0.41 & 4.63 & 4.59 & 16.6 & 101 & $83-120$ & 94 & 0 \\
\hline & & & 0.057 & 0.34 & 0.49 & 2.5 & & & & \\
\hline \multirow[t]{2}{*}{310} & 2.4(LHR) & 54.7 & - & 4.87 & 4.30 & 15.9 & 113 & $96-135$ & 68 & 0 \\
\hline & & & & 0.36 & 0.48 & 2.3 & & & & \\
\hline \multirow[t]{2}{*}{310} & 1(LHR) & 51.7 & 0.48 & 4.84 & 3.99 & 14.9 & 121 & $96-142$ & 13 & 0 \\
\hline & & & 0.081 & 0.39 & 0.50 & 2.7 & & & & \\
\hline \multirow[t]{2}{*}{440} & 47(HHR) & 76.8 & 1.62 & 4.48 & 3.90 & 13.6 & 115 & $90-148$ & 74 & 0 \\
\hline & & & 0.080 & 0.54 & 0.55 & 2.8 & & & & \\
\hline \multirow[t]{2}{*}{440} & 3.5(LHR) & 70.5 & 1.60 & 4.21 & 3.84 & 12.3 & 110 & $81-134$ & 44 & 0 \\
\hline & & & 0.106 & 0.49 & 0.52 & 2.6 & & & & \\
\hline \multirow[t]{2}{*}{440} & 1.4(LHR) & 68.3 & - & 4.13 & 3.75 & 11.9 & 110 & $95-155$ & 26 & 0 \\
\hline & & & & 0.47 & 0.53 & 2.5 & & & & \\
\hline \multirow[t]{2}{*}{600} & 97(HHR) & 81.7 & 3.72 & 4.26 & 3.67 & 12.5 & 116 & $96-153$ & 21 & 0 \\
\hline & & & 0.110 & 0.48 & 0.54 & 2.7 & & & & \\
\hline \multirow[t]{2}{*}{600} & 5(LHR) & 75.4 & 3.55 & 4.12 & 3.69 & 11.6 & 112 & $95-135$ & 49 & 0 \\
\hline & & & 0.140 & 0.45 & 0.37 & 2.0 & & & & \\
\hline \multirow[t]{2}{*}{600} & 2(LHR) & 73.5 & - & 4.13 & 3.56 & 11.1 & 116 & $100-138$ & 21 & 0 \\
\hline & & & & 0.32 & 0.25 & 1.5 & & & & \\
\hline
\end{tabular}

- Not measured 
Table 4 Properties of husked grains of Triticum aestivum carbonised in spikes at the indicated temperatures for 60 min at high (HHR) and low (LHR) heating rates; further explanations see Table 1

\begin{tabular}{|c|c|c|c|c|c|c|c|c|c|c|}
\hline $\begin{array}{l}\text { Temperature } \\
\left({ }^{\circ} \mathrm{C}\right)\end{array}$ & $\begin{array}{l}\text { Heating rate } \\
\left({ }^{\circ} \mathrm{C} / \mathrm{min}\right)\end{array}$ & $\begin{array}{l}\text { Mass loss } \\
(\%)\end{array}$ & $\% \mathrm{Rr}$ & $\begin{array}{l}L^{\mathrm{a}} \\
(\mathrm{mm})\end{array}$ & $\begin{array}{l}W^{\mathrm{a}} \\
(\mathrm{mm})\end{array}$ & $\begin{array}{l}A^{\mathrm{a}} \\
\left(\mathrm{mm}^{2}\right)\end{array}$ & $100^{\mathrm{a}} \mathrm{L} / \mathrm{W}$ & $\begin{array}{l}\text { Degree of } \\
\text { variation } \\
100 L / W\end{array}$ & $\begin{array}{l}\text { Grains with } \\
\text { protrusion }(\%)\end{array}$ & $\begin{array}{l}\text { Grains with } \\
\text { longitudinal } \\
\text { imprint(\%) }\end{array}$ \\
\hline \multirow[t]{2}{*}{310} & 26(HHR) & 56.6 & - & 5.40 & 4.21 & 17.1 & 128 & $104-157$ & 27 & 32 \\
\hline & & & & 0.34 & 0.27 & 1.5 & & & & \\
\hline \multirow[t]{2}{*}{310} & 2.4(LHR) & 55.3 & - & 5.55 & 4.10 & 16.8 & 135 & $112-154$ & 20 & 34 \\
\hline & & & & 0.42 & 0.32 & 2.2 & & & & \\
\hline \multirow[t]{2}{*}{440} & 47(HHR) & 73.7 & - & 5.02 & 3.51 & 13.4 & 143 & $112-175$ & 40 & 0 \\
\hline & & & & 0.25 & 0.19 & 1.0 & & & & \\
\hline \multirow[t]{2}{*}{440} & 3.5(LHR) & 67.2 & - & 5.02 & 3.68 & 14.0 & 136 & $116-157$ & 61 & 29 \\
\hline & & & & 0.42 & 0.35 & 1.7 & & & & \\
\hline \multirow[t]{2}{*}{600} & 97(HHR) & 77.6 & - & 4.44 & 3.36 & 11.3 & 132 & $109-153$ & 9 & 0 \\
\hline & & & & 0.48 & 0.36 & 1.7 & & & & \\
\hline \multirow[t]{2}{*}{600} & 5(LHR) & 72.0 & - & 4.75 & 3.38 & 12.0 & 141 & $122-150$ & 50 & 16 \\
\hline & & & & 0.46 & 0.31 & 1.7 & & & & \\
\hline
\end{tabular}

- Not measured

After the rupture, the volatile compounds are able to escape and may push part of the converted endosperm outside, forming the protrusions. Apparently the constitution of the pericarp determines if protrusions are formed and where on the surface of the pericarp they will occur.

Protrusions occur on grains of the dehusked and husked samples of $T$. dicoccum and T. aestivum in almost all the heating conditions applied (Tables 1, 2, 3, 4). The percentage of grains with protrusions in $T$. dicoccum varies from 81 to $0 \%$ and in T. aestivum from 94 to $9 \%$. The formation of protrusions strongly reduces when the heating rate is reduced (Tables 1, 2, 3, 4). At a LHR more time is available to release the volatile compounds to the external environment, which reduces the build-up of pressure within the grains and in turn fewer protrusions are formed. Concurrently, grains show fewer other distortions at a LHR.

When carbonised at a HHR, the percentage of grains with protrusions decreases with increasing temperature. At a HHR this percentage is higher than at a LHR, except at $600^{\circ} \mathrm{C}$ for $T$. dicoccum as well as $T$. aestivum grains. At higher temperatures the chemical reactions are rather violent and this seems to be in contradiction to the reduction of the number of grains with a protrusion at these temperatures (Tables 1, 2, 3, 4). No good explanation can be given for this phenomenon.

Husked grains generally have a lower percentage of grains with protrusions than dehusked grains, but there are also some exceptions as can be seen in the results of T. aestivum grains carbonised at a $\mathrm{HHR}$ at 440 and $600^{\circ} \mathrm{C}$.

It is obvious that the formation of protrusions on the outside of the grains occurs frequently under the present experimental conditions. However, in the relevant archaeological literature hardly any observations of protrusions are mentioned. This could mean that grains with protrusions have been an easy target for attack by microorganisms or other means of decay, or that distortion of the grains makes them not very suitable for identification. But the presence of protrusions could give valuable information on the types of fire causing this feature, which is useful for other purposes of archaeological research.

Mass loss

The mass loss of the samples increases with increasing oven temperatures, which corresponds with results obtained in studies describing the carbonisation of seeds relevant for archaeobotany (Braadbaart 2004; Braadbaart et al. 2006). However, in experiments with an identical final temperature the calculated mass loss of samples carbonised at a LHR is lower than the mass loss attained at a HHR (Tables 1, 2). T. dicoccum grains carbonised at a HHR at, for example, $440^{\circ} \mathrm{C}$ show a mass loss of $75.9 \%$, but when heated in $120 \mathrm{~min}$ to $440^{\circ} \mathrm{C}$ (LHR) the mass loss was 69.5 and $67.3 \%$ when heated in $300 \mathrm{~min}$ to this temperature.

When the volatile compounds traverse the residues on their way to the external environment, secondary reactions will occur between the converting solids of the endosperm and these volatiles. In the case of a LHR, the residence time of the volatiles within the heated grains is longer compared to a HHR and more time is available for secondary reactions. Thus more secondary compounds with identical chemical structure are formed and in turn less 
Table 5 Shrinkage (\%) of length and swelling (\%) of width of husked and dehusked grains of Triticum dicoccum (variety EIT) and bread (variety Sunnan) wheat as a result of carbonization for $60 \mathrm{~min}$ at the indicated temperatures and heating rates

$H H R$ High heating rate; $L H R$ low heating rate

${ }^{a}$ Percentages based on mean values of samples with $N=30$

\begin{tabular}{|c|c|c|c|c|c|c|c|}
\hline & & \multicolumn{3}{|c|}{$\begin{array}{l}\text { Length (\% shrinkage } \\
\text { relative to uncarbonized } \\
\text { length of } 8.08 \mathrm{~mm} \text { ) }\end{array}$} & \multicolumn{3}{|c|}{$\begin{array}{l}\text { Width (\% swelling relative to } \\
\text { uncarbonized width of } 2.82 \mathrm{~mm} \text { ) }\end{array}$} \\
\hline \multicolumn{8}{|c|}{ Triticum dicoccum } \\
\hline & & $310^{\circ} \mathrm{C}$ & $440^{\circ} \mathrm{C}$ & $600^{\circ} \mathrm{C}$ & $310^{\circ} \mathrm{C}$ & $440^{\circ} \mathrm{C}$ & $600^{\circ} \mathrm{C}$ \\
\hline \multirow[t]{2}{*}{ Dehusked } & HHR & $21^{\mathrm{a}}$ & 27 & 27 & 44 & 27 & 19 \\
\hline & LHR & 16 & 25 & 31 & 36 & 23 & 15 \\
\hline Husked & HHR & 9 & 20 & 28 & 38 & 16 & 6 \\
\hline (Spike) & LHR & 7 & 20 & 28 & 40 & 20 & 8 \\
\hline \multicolumn{8}{|c|}{ Triticum aestivum } \\
\hline & & \multicolumn{3}{|c|}{ Uncarbonized length $5.70 \mathrm{~mm}$} & \multicolumn{3}{|c|}{ Uncarbonized width $3.39 \mathrm{~mm}$} \\
\hline \multirow[t]{2}{*}{ Dehusked } & HHR & 19 & 21 & 24 & 35 & 16 & 8 \\
\hline & LHR & 15 & 27 & 28 & 22 & 12 & 7 \\
\hline Husked & HHR & 5 & 12 & 22 & 24 & 4 & 0 \\
\hline (Spike) & LHR & 3 & 12 & 17 & 21 & 9 & 0 \\
\hline
\end{tabular}

mass loss is observed. As the chemical structure does not change, the reflectance does not change either, and the temperature at which the grains have been carbonised can thus still be measured. In general it was observed that at a LHR the grains become less distorted and more compact, whereby $T$. dicoccum and T. aestivum show an identical development.

With increasing temperature the amount of volatiles increases and in turn the mass loss increases. The grains will thus become smaller, showing a further shrinkage of the length and a decrease in swelling of the width.

\section{Length and width}

The measurements of length and width of the investigated grains show that with increasing temperature the length decreases and the width increases, as expected from earlier experiments (Braadbaart and van Bergen 2005; Hopf 1955; Boardman and Jones 1990). In contrast, the influence of the heating rate on the change of length and width of dehusked as well as husked grains is minor (Table 5).

The results of the experiments at the three selected temperatures at a HHR together with the additional experiments at the full range of temperatures at a HHR are summarized in Fig. 1. Since the heating rate does not have a great influence on these three characters, only the results for a HHR are given. The length of the grains is characterized by a continuous shrinkage with increasing temperature. The width increases rapidly up to $270^{\circ} \mathrm{C}$, but at higher temperatures it increases at a slower rate. As a result, up to a temperature of $250^{\circ} \mathrm{C}$, the area increases and at higher temperatures it decreases again. Between 370 and $400^{\circ} \mathrm{C}$ the original uncarbonised area is reached again, which decreases again with increasing temperature so that grains now become smaller than their original size.

The changes of length and width are different for dehusked and husked grains. From the results for the changes of length and width (Table 5), it can be concluded that at $310^{\circ} \mathrm{C}$ husked grains become larger, while at $600^{\circ} \mathrm{C}$ they have become smaller compared to dehusked grains. Apparently, at $310^{\circ} \mathrm{C}$, the tough glumes present on the husked grains do not prevent the grains from increasing in width, while on the other hand the shrinkage of the length is strongly reduced. The latter could be caused by friction between grains and glumes. One should take into consideration that the physical properties of the glumes have also changed because of their carbonisation. At $600^{\circ} \mathrm{C}$ the opposite is observed and husked grains are smaller than dehusked grains. Now the shrinkage of the lengths of dehusked and husked grains is identical, but the swelling of the width of the husked grains is reduced. An explanation for this development could be that carbonised glumes have become very rigid at this temperature, which would prevent the swelling of the grains. Although it is assumed that glumes in $T$. aestivum are less developed than those of $T$. dicoccum, both species react in a similar way. Apparently when glumes are carbonised this difference is not of importance any more. However, it is noted that the differences in size between dehusked and husked T. aestivum grains are smaller than for $T$. dicoccum grains.

To illustrate the results of experiments (see Fig. 1; Tables 1, 2, 3, 4), in which dehusked grains were carbonised at a HHR, the factor $100 \mathrm{~L} / \mathrm{W}$ is plotted as a function of the temperature (Fig. 2). For both varieties the slenderness of the grains decreases until a temperature of around $300^{\circ} \mathrm{C}$ is reached and remains more or less constant at higher temperatures. It is well known that $T$. dicoccum grains are 

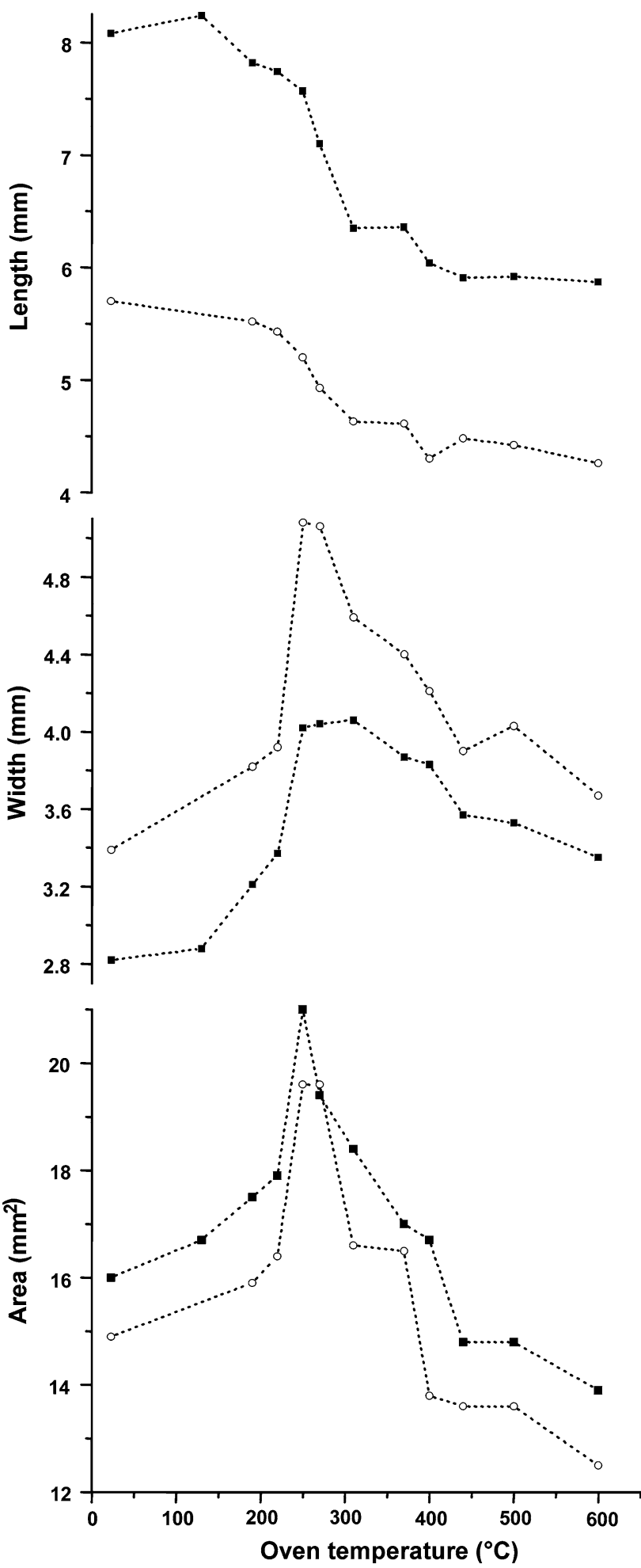

Fig. 1 Change of length, width and area of samples $(N=30)$ of Triticum dicoccum and $T$. aestivum grains, carbonised at a high heating rate, as a function of the oven temperature in ${ }^{\circ} \mathrm{C}$. Filled square T. dicoccum and open circle T. aestivum

more slender than grains of T. aestivum (Hubbard 1992). This is once more confirmed by the mean $100 \mathrm{~L} / \mathrm{W}$ of the sample of untreated grains of $T$. dicoccum, which is 287

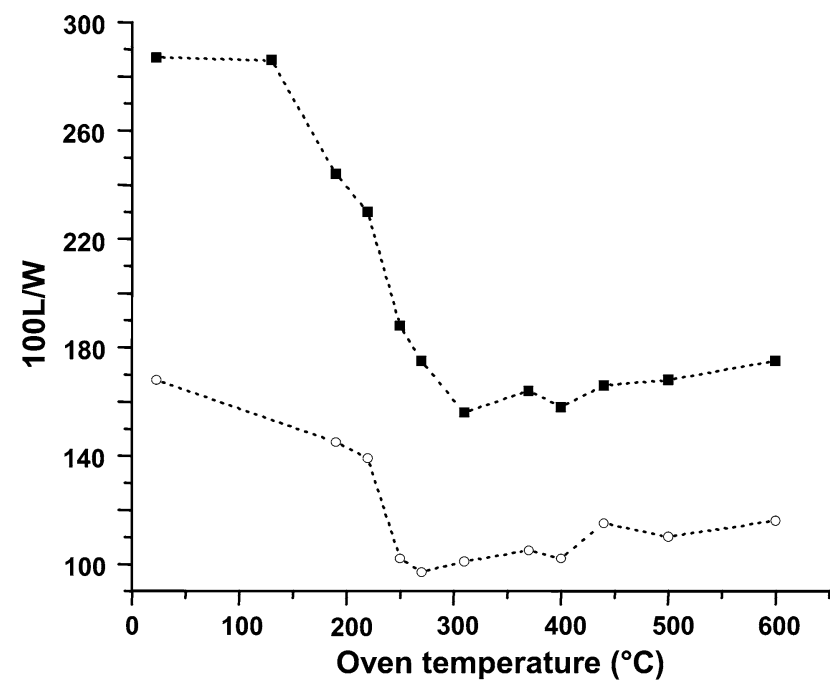

Fig. 2 Change of the mean of the factor $100 \mathrm{~L} / W$ of samples $(N=30)$ of dehusked grains of Triticum dicoccum and T. aestivum, as a function of the oven temperature in ${ }^{\circ} \mathrm{C}$. Samples carbonised at a high heating rate. Filled square T. dicoccum and open circle T. aestivum

with a degree of variation around the mean of 242 to 320 , while for T. aestivum grains the mean of this factor is 168 with a degree of variation around the mean of 154 to 200. As a result of carbonisation the mean of $100 \mathrm{~L} / \mathrm{W}$ decreases to around 170 for $T$. dicoccum and to 115 for T. aestivum, showing a clear difference still between these ratios for both species at temperatures higher than $300^{\circ} \mathrm{C}$.

Husked grains, after removal of the glumes, have a larger mean $100 \mathrm{~L} / \mathrm{W}$ compared to dehusked grains and the degree of variation shows that there is always a difference between both species (Tables 2,4). This is even true for single grains. For dehusked grains the situation is different: for the samples heated at 310,440 and $600^{\circ} \mathrm{C}$ an overlap in the degree of variation is observed. The results show that grains of $T$. dicoccum and $T$. aestivum can reach an identical $100 \mathrm{~L} / \mathrm{W}$ at these temperatures. To distinguish between the two species, an assemblage of at least 30 grains should be used, so the use of this method for single grains is problematic. In an earlier study it was suggested that the slenderness of both species became similar and separation between the two species based on the shape was not possible (Braadbaart et al. 2005). This suggestion was based on a comparison between dehusked single grains of each species and appears to be still partly valid.

Photographs were made of one or two selected grains from each sample that was carbonised in this study (Figs. 3, 4, 5). The results show that grains carbonised at a HHR are rather distorted, while at a LHR more compact grains are formed, which are comparable with grains described from archaeological assemblages. This is even truer for grains that have been carbonised in spikes. With $T$. 
Fig. 3 Photographs of dehusked uncarbonised and carbonised grains of Triticum dicoccum, carbonised at the indicated temperatures and heating rates

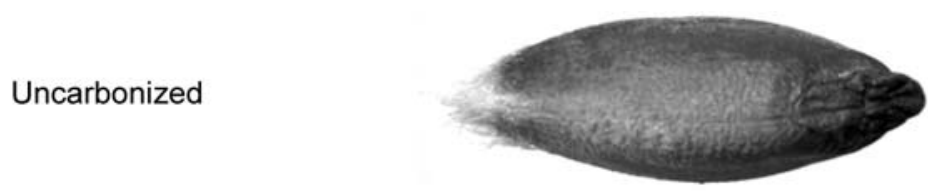

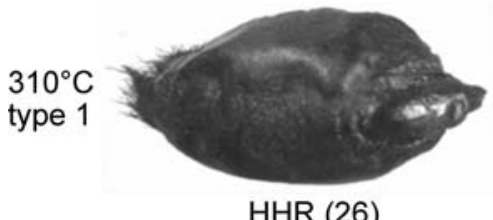

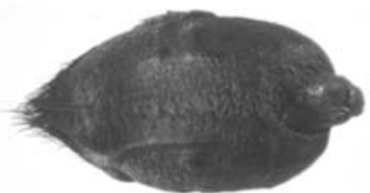

LHR (2.4)

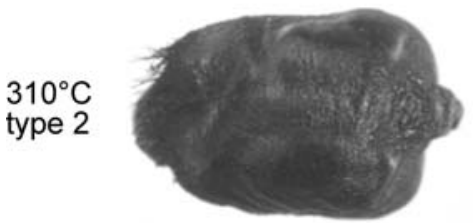

HHR (26)

$440^{\circ} \mathrm{C}$ type 1

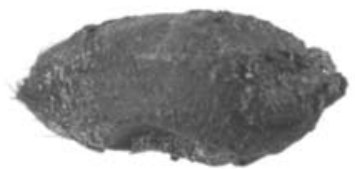

HHR (47)

$440^{\circ} \mathrm{C}$ type 2

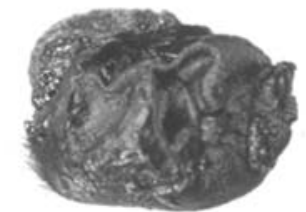

HHR (47)

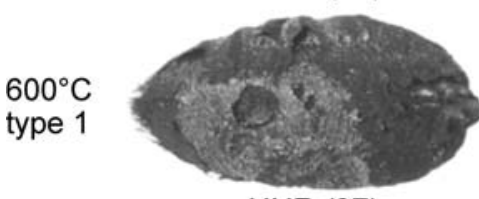

HHR (97)

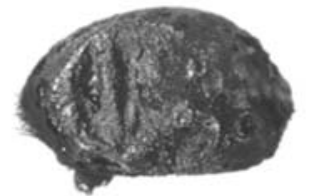

HHR (97)

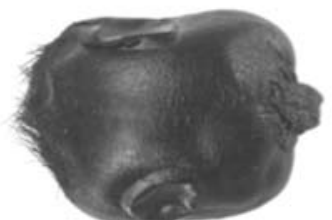

LHR (2.4)

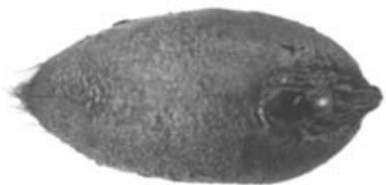

LHR (3.5)

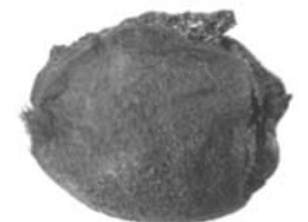

LHR (3.5)

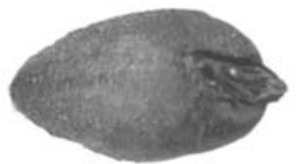

LHR (5.0)

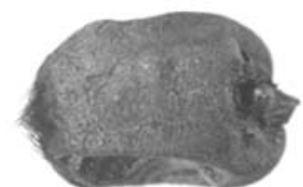

LHR (5.0)

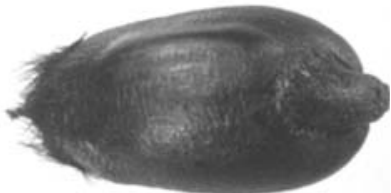

LHR (1.0)

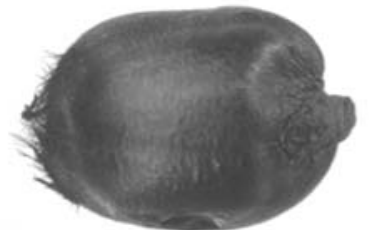

LHR (1.0)
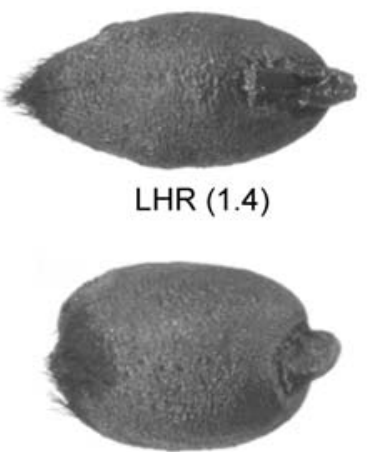

LHR (1.4)

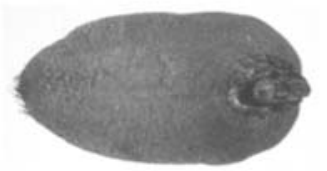

LHR (2.0)

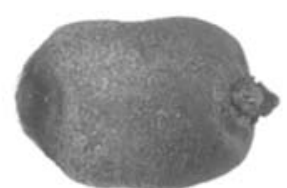

$\operatorname{LHR}(2.0)$
$\mathrm{HHR}(97)=$ High heating rate of $97^{\circ} \mathrm{C} / \mathrm{min}$ $\operatorname{LHR}(5.0)=$ Low heating rate of $5.0^{\circ} \mathrm{C} / \mathrm{min}$ dicoccum grains, different types are present. This should be considered as a transition that shows on the one hand slender grains (type 1), like uncarbonised grains, and on the other hand a rounder type of grain (type 2) (Fig. 4). The latter type has more of the characteristics that are usually attributed to $T$. aestivum grains.
Flanks

After carbonisation the normal convex flanks of grains have often changed into concave flanks in both dehusked and husked varieties. But the presence of concave flanks is mainly restricted to grains carbonised at a HHR and at 
Fig. 4 Photographs of dehusked uncarbonised and carbonised grains of Triticum aestivum, carbonised at the indicated temperatures and heating rates

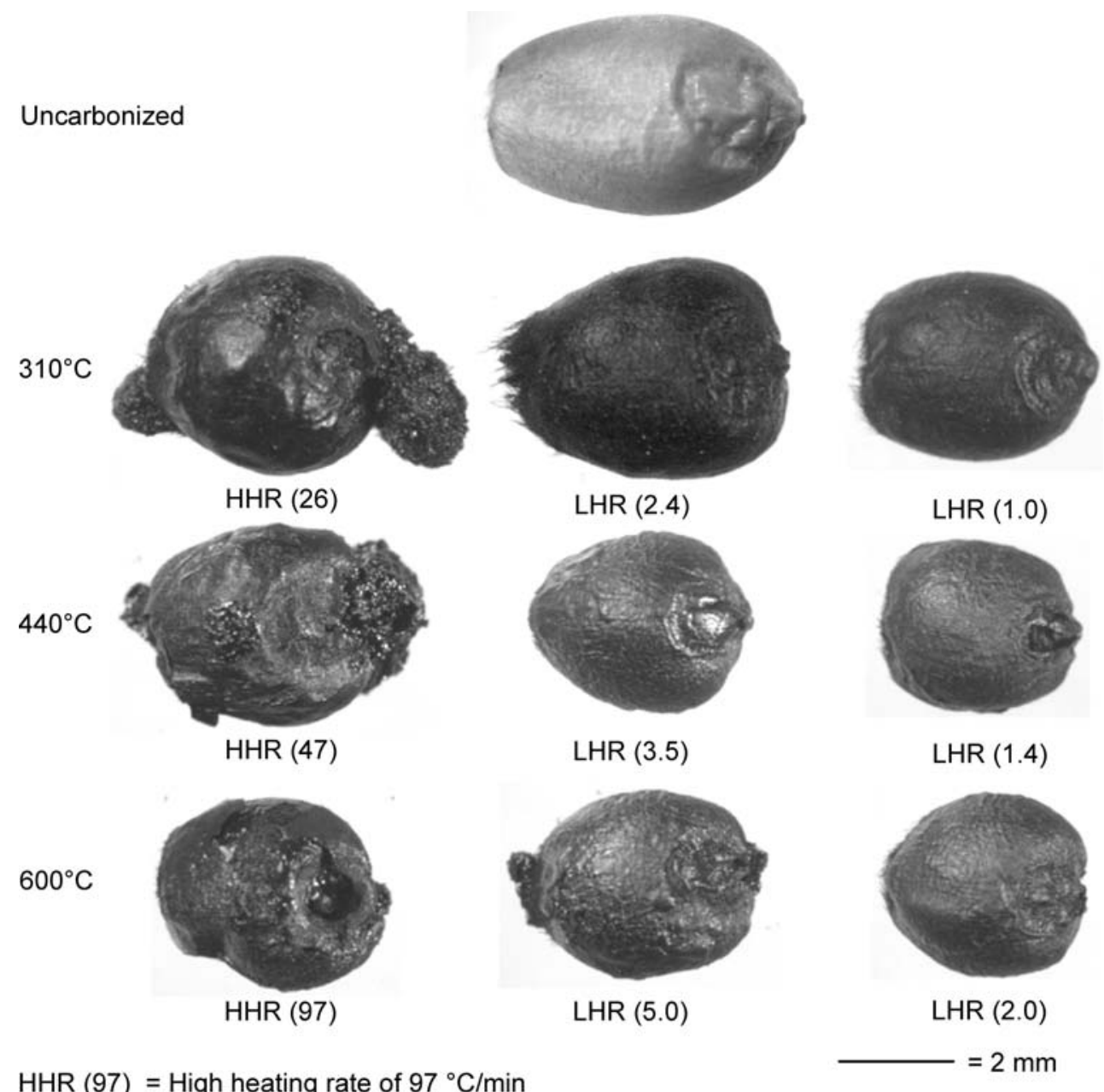

$\mathrm{HHR}(97)=$ High heating rate of $97^{\circ} \mathrm{C} / \mathrm{min}$

$\operatorname{LHR}(5.0)=$ Low heating rate of $5.0^{\circ} \mathrm{C} / \mathrm{min}$ temperatures higher than $300^{\circ} \mathrm{C}$ (Fig. $4,440^{\circ} \mathrm{C} \mathrm{HHR}$ ). Between 30 and $40 \%$ of the grains carbonised in this way have concave flanks. Occasionally grains become concave at a LHR (Fig. $3,310^{\circ} \mathrm{C}$ type $2 \mathrm{LHR} ; 600^{\circ} \mathrm{C}$ type $2 \mathrm{LHR}$ ). The sudden release of volatile compounds causes a low pressure within the grains, so that the higher atmospheric pressure will push the flanks inwards. It is noted that the flanks must still have a constitution that will allow this kind of deformation.

\section{Reflectance}

Measurements of the reflectance on wheat grains, carbonised for $60 \mathrm{~min}$ at a range of temperatures, have been performed before (Braadbaart et al. 2004). These results together with the present results are presented together in Fig. 6. From $270^{\circ} \mathrm{C}$ the reflectance could be measured, which rises slowly with increasing temperature up to $400^{\circ} \mathrm{C}$. Thereafter the reflectance rises more rapidly. In spite of the differences in mass loss the reflectances measured on samples that have been carbonised at similar temperatures are identical. There is no difference observed between $T$. dicoccum and $T$. aestivum, and dehusked and husked grains.

Reflectance can be measured on samples carbonised at $270^{\circ} \mathrm{C}$ and above, when aromatic structures have been formed. In the range between 270 and $370^{\circ} \mathrm{C}$, however, the temperature cannot be determined unless the time of exposure is known (Braadbaart 2004, Fig. 7.3). Obviously, the time of exposure of remains recovered from archaeological sites is never known. From $370^{\circ} \mathrm{C}$ and higher or with reflectances higher than $0.8 \% \mathrm{Rr}$ this method can be applied without restrictions.

The surface of wheat grains becomes shinier when carbonised at temperatures higher than $440^{\circ} \mathrm{C}$. This feature is comparable with the increasing reflectance measured on polished specimens as described above. Cellulose, the main constituent of the pericarp, will also be converted into aromatic compounds like the starch present in the 
Triticum dicoccum

Triticum aestivum

$310^{\circ} \mathrm{C}$

HHR (26)
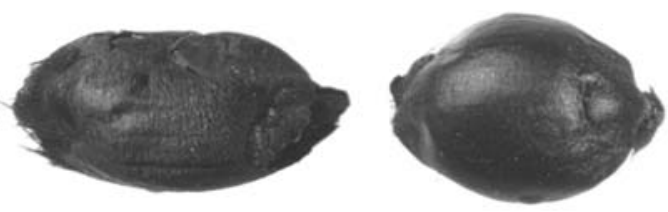

$310^{\circ} \mathrm{C}$

$\operatorname{LHR}(2.4)$
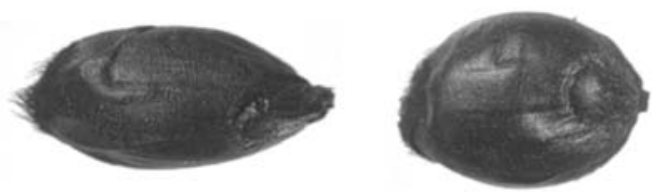

$440^{\circ} \mathrm{C}$

$\mathrm{HHR}(47)$
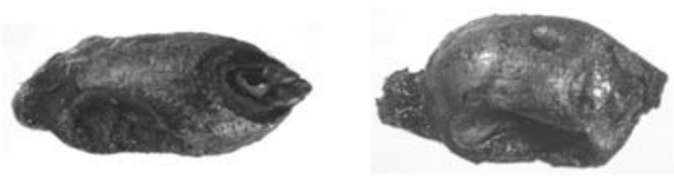

$440^{\circ} \mathrm{C}$ $\operatorname{LHR}(3.5)$
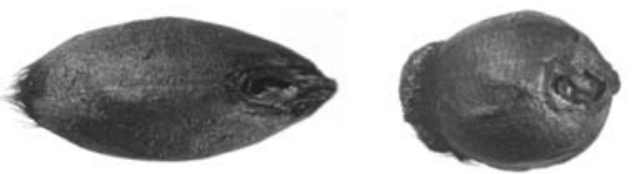

$600^{\circ} \mathrm{C}$

HHR (97)
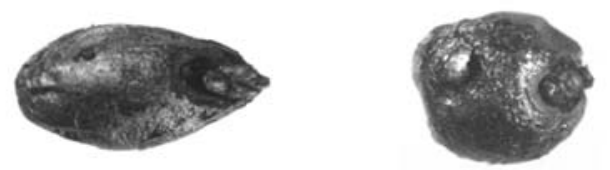

$600^{\circ} \mathrm{C}$

$\operatorname{LHR}(5.0)$
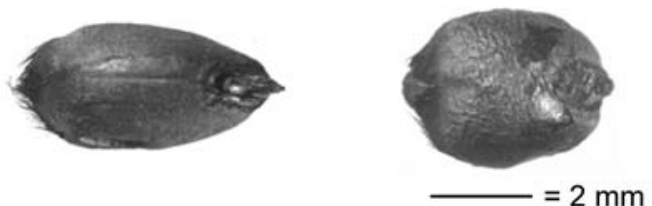

$\operatorname{HHR}(97)=$ High heating rate of $97^{\circ} \mathrm{C} / \mathrm{min}$ $\operatorname{LHR}(5.0)=\mathrm{Low}$ heating rate of $5.0^{\circ} \mathrm{C} / \mathrm{min}$

Fig. 5 Photographs of grains of Triticum dicoccum and T. aestivum, carbonised in spikes at the indicated temperatures and heating rates

endosperm. With increasing temperature, the optical properties will change in such a way that more light will be reflected from the surface thus causing the shinier look.

Morphological changes after carbonisation

Some important aspects of carbonised archaeological grains, such as the lack of protrusions, or in the case of T. dicoccum, the slender shape, are not replicated in the present set of experiments. However, carbonisation is only the first of a series of transformations that may occur to the grains. After burial in the soil, further transformations are likely as a result of physical, biological and chemical processes. Concurrently, before becoming an object of

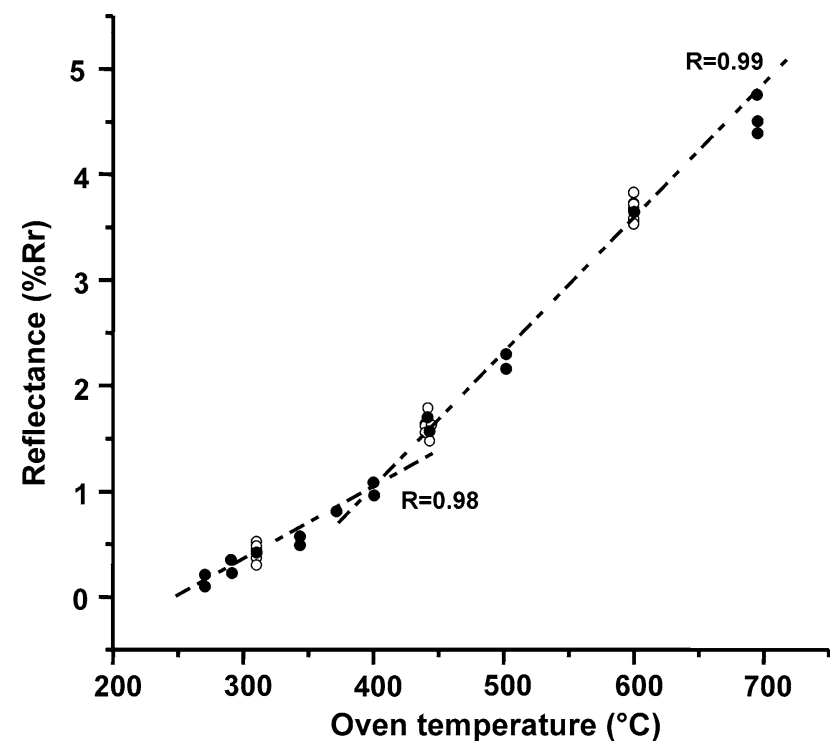

Fig. 6 The reflectance $(\% \mathrm{Rr})$ measured on polished surfaces of Triticum dicoccum and T. aestivum grains, carbonised for $60 \mathrm{~min}$ at a rapid and slow heating rate, as a function of the oven temperature. Filled circle results from the present study and open circle results from earlier study (see text)

investigation by archaeobotanists, the grains may be affected by the methods of recovery and analytical processes. All these processes may change the morphology of the grains and could explain, at least partly, some of the aspects that are not replicated.

\section{Conclusions: consequences for archaeobotany?}

To determine the temperature at which carbonisation of wheat grains occurred, the measurement of the reflectance on polished surfaces of carbonised grains is an easy and cheap method, but only for temperatures higher than $370^{\circ} \mathrm{C}$. In the range between 270 and $370^{\circ} \mathrm{C}$ certain restrictions are applicable. In combination with morphological data the measurement of the reflectance could be a useful tool for archaeological research.

When grains are carbonised at temperatures higher than $370^{\circ} \mathrm{C}$ the total mass loss can be determined. This allows for the determination of the original weight of grains before they were carbonised.

The presence of protrusions on carbonised grains recovered from the archaeological record may give valuable information on types of fire, and it is therefore recommended to include this information in the relevant reports, even when identification is not possible.

The uncarbonised T. dicoccum grains used in this study do not show a clear presence of imprints and accordingly no imprints are observed on carbonised dehusked grains (Tables 1, 2, 3, 4). On husked grains, imprints are present 
in both species. The percentage of grains with imprints on $T$. dicoccum grains is higher than on $T$. aestivum grains, but the latter still show a considerable number of grains with imprints. Grains of both species carbonised at a LHR at 440 and $600^{\circ} \mathrm{C}$ do not show any imprints. In archaeological contexts, $T$. dicoccum is typically stored as spikelets and $T$. aestivum as grains. It is therefore not surprising that archaeological $T$. dicoccum grains typically bear imprints and $T$. aestivum do not. Difficulties in the use of this criterion may arise when $T$. dicoccum grains have been carbonised outside the spikelet.

The occurrence of grains with concave flanks in both $T$. dicoccum and T. aestivum is just the result of the carbonisation process and not of any sample related variables such as the water content.

The mean shape factor $100 \mathrm{~L} / W$ is a useful tool to distinguish between $T$. dicoccum and $T$. aestivum grains as long as the population of the available sample is larger than 30. For single grains the use of this factor is problematic, as $T$. dicoccum grains may become as round as $T$. aestivum grains when dehusked grains are carbonised.

Distinction between husked and dehusked grains is possible when using the mean shape factor for samples containing 30 grains or more.

A low heating rate, under the present experimental conditions, seems to be the way of obtaining grains that are comparable to those recovered from archaeological sites. This would mean that the majority of the latter grains have been carbonised at a LHR and therefore not in a direct contact with the heat source.

Although this group of experiments has failed to replicate some important aspects of archaeological grains, such as the protrusions and the slender shape of $T$. dicoccum, it is important to note that after carbonisation a range of transformations may change the morphology of the grains. Further investigation is needed to establish the influence of these transformations on much archaeological material.

Acknowledgments This article is dedicated to Professor Corrie Bakels on the occasion of her 65th birthday. The author wishes to express his gratitude to her for introducing him to this research and for stimulating discussions. The comments of L.I. Kooistra (Zaandam) and M. Nesbitt (London), which led to a significant improvement of the text, are greatly appreciated.

\section{References}

Boardman S, Jones G (1990) Experiments on the effects of charring on cereal plant components. J Archaeol Sci 17:1-11

Braadbaart F (2004) Carbonization of peas and wheat. A laboratory study. Doctoral thesis, University of Leiden. www.amolf.nl/ publications/theses

Braadbaart F, van Bergen PF (2005) Digital imaging analysis of size and shape of wheat and pea upon heating under anoxic conditions as a function of the temperature. Veget Hist Archaeobot 14:67-75

Braadbaart F, van der Horst J, Boon JJ, van Bergen PF (2004) Laboratory simulations of the transformation of emmer wheat as a result of heating: the change of the physical, bulk chemical and molecular composition. J Therm Anal Calorim 77:957-973

Braadbaart F, Bakels CC, Boon JJ, van Bergen PF (2005) The selection of a variety of emmer wheat for heating experiments under anoxic conditions. Archaeometry 47:101-112

Braadbaart F, Wright PJ, van der Horst J, Boon JJ (2006) A laboratory simulation of the carbonization of sunflower achenes and seeds. J Anal Appl Pyrolysis 78:316-327

Carr AD, Williamson JE (1989) The relationship between aromaticity, vitrinite reflectance and maceral composition of coals: implications for the use of vitrinite reflectance as a maturation parameter. Adv Org Geochem 6:313-323

Hillman G (2001) Archaeology, percival, and the problems of identifying wheat remains. In: Caligari PDS, Brandham PE (eds) Wheat taxonomy: the legacy of John Percival. Linnean Society, London. Linnean Special Issue 3:27-36

Hillman GC, Mason S, de Moulins D, Nesbitt M (1996) Identification of archaeological remains of wheat: the 1992 London workshop. Circaea 12:195-209

Hopf M (1955) Formveränderungen von getreidekörnern beim verkohlen. Ber Dtsch Bot Ges 68:191-193

Hubbard RNLB (1992) Dichotomous keys for the identification of the major old world crops. Rev Palaeobot Palynol 73:105-115

International standard ISO 7404-2 (1985) Methods for the petrographic analysis of bituminous coal and anthracite. Part 2: method of preparing coal samples, ref. no. ISO 7404/2-1985(E)

International standard ISO 7404-5 (1994) Methods for the petrographic analysis of bituminous coal and anthracite. Part 5: method of determining microscopically the reflectance of vitrinite, ref. no. ISO 7404/5-1994(E)

Maier U (1996) Morphological studies of free-threshing wheat ears from a Neolithic site in southwest Germany, and the history of the naked wheats. Veget Hist Archaeobot 5:39-55

Papa C (1995) The "farre de Montelione": landrace and representation. In: Padulosi S, Hammer K, Heller J (eds) From staple crop to extinction? The archaeology and history of the hulled wheats. Hulled wheats. Proceedings of the first international workshop on hulled wheats. International Plant Genetic Resources Institute, Rome, pp 154-168 